\title{
Article \\ Clinical Impact of Supraclavicular Lymph Node Involvement of Stage IIIC Non-Small Cell Lung Cancer Patients
}

\author{
Sunmin Park (D), Won Sup Yoon, Mi Hee Jang and Chai Hong Rim * \\ Department of Radiation Oncology, Ansan Hospital, Korea University, 123 Jeokgeum-ro, Danwon-gu, \\ Ansan 15355, Gyeong-Gi Do, Korea; sunmini815@gmail.com (S.P.); irionyws@korea.ac.kr (W.S.Y.); \\ 4060622@naver.com (M.H.J.) \\ * Correspondence: crusion3@naver.com; Tel./Fax: +82-31-412-6850
}

Citation: Park, S.; Yoon, W.S.; Jang, M.H.; Rim, C.H. Clinical Impact of Supraclavicular Lymph Node Involvement of Stage IIIC Non-Small Cell Lung Cancer Patients. Medicina 2021, 57, 301. https://doi.org/ 10.3390/medicina57030301

Academic Editor: Silvia Morbelli

Received: 5 February 2021

Accepted: 19 March 2021

Published: 23 March 2021

Publisher's Note: MDPI stays neutral with regard to jurisdictional claims in published maps and institutional affiliations.

Copyright: (c) 2021 by the authors. Licensee MDPI, Basel, Switzerland. This article is an open access article distributed under the terms and conditions of the Creative Commons Attribution (CC BY) license (https:// creativecommons.org/licenses/by/ $4.0 /)$.
Abstract: Background and Objective: Investigations on the clinical impact of supraclavicular lymph node (SCN) involvement in stage IIIC non-small cell lung cancer (NSCLC) remain scarce. We evaluated the oncological outcomes of definitive radiochemotherapy and the clinical significance of SCN involvement. Materials and Methods: Between November 2009 and June 2019, a total of 40 patients with N3-positivity and NSCLC were evaluated. Most patients received concomitant chemotherapy, but six patients who received radiotherapy (RT) alone were also included. Twenty-one patients $(52.5 \%)$ received 3D-conformal RT (3DCRT), and the remainder received intensity-modulated RT (IMRT). Results: The median follow-up duration was 10.7 months (range: 1.7-120.6 months). Median overall survival (OS) and cause-specific survival (CSS) times were 10.8 months and 16.3 months, respectively. Among the 40 patients, 17 (42.5\%) had SCN involvement. SCN involvement negatively affected progression-free survival (hazard ratio (HR): 2.08, 95\% confidence interval (CI): 1.04-4.17, $p=0.039$ ) and local control (HR: 3.05, 95\% CI: 1.09-8.50, $p=0.034)$. However, IMRT use was correlated with higher local control (HR: $0.28,95 \%$ CI: 0.09-0.86, $p=0.027$ ). Grade $\geq 3$ esophagitis and pneumonitis accounted for $7.5 \%$ and $15.0 \%$ of all cases, respectively. A higher RT dose (mean dose: 66.6 vs. $61.7 \mathrm{~Gy})$ was significantly correlated with grade $\geq 3$ pneumonitis $(p=0.001)$. RT modality was a significant factor ( $p=0.042$, five of six cases occurred in the IMRT group). Conclusions: SCN involvement could negatively affect oncologic outcomes of stage IIIC NSCLC patients. High-dose irradiation with IMRT could increase local control but may cause lung toxicities.

Keywords: non-small cell lung carcinoma; radiochemotherapy; intensity-modulated radiotherapy; supraclavicular lymph node; NSCLC IIIC

\section{Introduction}

Stage III non-small cell lung cancer (NSCLC) is challenging to cure, despite the latest advances in technology. NSCLC continues to demonstrate a low rate of long-term survival. Because the oncological benefit is insignificant with surgical management, radiochemotherapy is considered the current standard modality, especially for patients with stage IIIB or higher $[1,2]$. In staging up to the 7 th edition of the American Joint Committee on Cancer (AJCC), patients with N3 nodal involvement or T4N2 were classified as stage IIIB [3]. N3 nodal involvement has been reported as a possible factor that lowers survival in stage IIIB NSCLC patients [4,5]. In the recent staging of the 8th edition of AJCC, stage IIIB in the previous system was further subdivided into stage IIIC for patients with N3 disease. According to a recent study conducted by the International Association for the Study of Lung Cancer (IASLC) staging project, the median and 5-year rates of survival of patients with N3 disease (10 months and 9\%) were significantly lower than those of N2 (17 months and $23 \%$ ) [6].

A meta-analysis conducted by Auperin et al. revealed that patients with locally advanced NSCLC gained survival benefit from radiochemotherapy, which is thought to be 
due to the significant decrease in locoregional recurrence [7]. Currently, a dose of at least 60 Gy of radiotherapy (RT) for patients with stage III or higher NSCLC is regarded as the standard [8]. However, from the perspective of a radiation oncologist, it might not be easy to safely deliver more than 60 Gy of RT to patients with stage III or higher. In particular, patients with N3 disease inevitably have a large target volume; the presence of contralateral mediastinal or supraclavicular lymph nodes (SCNs) makes it difficult to maintain the safety dose limit to the lung or mediastinal organs (e.g., esophagus) during treatment $[9,10]$.

Most of the previous studies have reported heterogeneous patients at stage III or higher. Because stage IIIC is a new categorization, studies regarding the clinical outcomes are scarce. Furthermore, a few studies have investigated the clinical impact of SCN involvement compared to contralateral lymph node metastases [11,12]. In this study, we report the clinical experience of N3-IIIC patients who underwent definitive radiochemotherapy in mid-sized tertiary hospitals to discuss its efficacy and feasibility, as well as the clinical impact of SCN involvement.

\section{Materials and Methods}

\subsection{Patient Recruitment and Evaluation}

A chart review was performed for NSCLC patients who underwent definitive RT between November 2009 and June 2019 (IRB number: 2020AS0244). The inclusion criteria were as follows: (1) pathologically confirmed NSCLC; (2) categorized as stage IIIC NSCLC according to the AJCC 8th staging system; (3) receipt of definitive RT with a prescribed dose of $\geq 60 \mathrm{~Gy}$; and (4) no evidence of uncontrolled lesions at any site other than the lung at the start of RT. The vast majority of chemotherapy regimen was platinum and taxane based. The primary endpoints of the present study were overall survival (OS) and cause-specific survival (CSS). Progression-free survival (PFS), local control (LC), and grade $\geq 3$ complications were the secondary endpoints. Complications related to RT were evaluated according to the Common Terminology Criteria for Adverse Events (CTCAE; version 4.03). Local recurrence was defined as the development of a new lesion or an increase in tumor size in the treated area (in-field failure). Disease progression was defined as the development of recurrence after RT. Distant metastases were defined as intrapulmonary out-of-field recurrence and/or distant recurrence at any site outside of the lung. Overall, PFS and recurrence-free survival were estimated from the date of RT initiation to the date of death, the last follow-up examination, or the date of tumor progression and recurrence, whichever occurred first. An equivalent dose of 2 Gy per fraction RT (EQD2) was calculated from the prescribed dose using an $\alpha / \beta$ ratio of 10 . All patients were followed up with at 1 month after radiation and at 3- or 6-month intervals thereafter. At each follow-up, a detailed questionnaire on clinical status and a physical examination was administered to the patients, along with basic laboratory studies, liver and renal function tests, chest computed tomography (CT), and/or whole-body positron emission tomography/CT (PET/CT) as needed.

\subsection{Statistical Analysis}

For survival and univariate analyses, Kaplan-Meier estimation [13] and log-rank tests were performed. The Cox proportional hazards model [14] was used for multivariate analyses, using the backward elimination method. Considering the small number of patients and the possible suppression factor effect [15] (i.e., in a small series, factors that have possible mutual influence are likely to suppress the effects of other factors), all covariates evaluated in univariate analysis were assessed in multivariate analysis. Survival analyses were performed using SPSS v20.0 (IBM Corporation, Armonk, NY, USA), and multivariate analysis was performed using web-based Analysis with R 4.0 (available at https:/ / cardiomoon.shinyapps.io/webr/, assessed from 15 December 2020 to 14 January 2021). There were no considerable missing clinical data regarding statistical analyses. 


\subsection{Radiotherapy Procedure}

In our center, most patients with stage III or higher NSCLC were prescribed with either 60-66 Gy in 30 fractions or $63 \mathrm{~Gy}$ in 35 fractions. CT simulations were performed using the Philips Brilliance Big Bore CT scanner (Philips Healthcare, Cleveland, OH, USA). Patients were immobilized using Vac-Lok (KIKWANG MEDICAL, Seoul, Korea) and wing board (CIVCO, Kalona, IA, USA). A contrast-enhanced four-dimensional CT (4DCT) scan with 2$3 \mathrm{~mm}$ slice thickness was performed using the Varian RPM system (Varian Medical Systems, Palo Alto, CA) while monitoring respiratory signals. The 4DCT images were sorted into 10 phases such that the $0 \%$ respiratory phase corresponded to peak inhalation and the $50 \%-60 \%$ phase corresponded to peak exhalation. The gross target volume (GTV) can include the entire primary lung mass, with lymph nodes that have regional involvement contoured in the CT scan in the $50 \%$ or $60 \%$ phase, and the internal target volume (ITV) was set to be expanded by reflecting the movement in all phases. Diagnostic PET/CT was co-registered with simulation CT for target contouring if possible. Planning target volume (PTV) was set with a margin of 5-7 mm from ITV. Gating was not performed because the ITV reflected the movements of all phases in free breathing. The setup was performed by applying a tattoo to the patient, and daily pre-treatment cone-beam computed tomography (CBCT) matching was verified by a physician. Image guidance was performed by matching the bony landmark and the GTV contour.

\section{Results}

\subsection{Patient Characteristics}

Between November 2009 and June 2019, a total of 40 patients met the enrollment criteria and were included in the analysis. Most patients were male $(80.0 \%)$; their median age was 67.5 years (range, $44.0-89.0$ years). Radiochemotherapy was performed in the vast majority of patients $(85 \%)$; six patients who were initially recommended to undergo radiochemotherapy, but received RT alone for medical reasons (not related to cancer) or patients' willingness were also included. Most patients (87.5\%) had an Eastern Cooperative Oncology Group (ECOG) performance status score of 0 or 1. Seventeen of 40 patients $(42.5 \%)$ had SCN involvement, whereas the remaining patients had contralateral mediastinal involvement. A total of $52.5 \%$ of patients received 3DCRT, and the rest received IMRT. In EQD2, the mean doses ( \pm standard deviation) delivered with 3DCRT and IMRT were $60.6( \pm 6.0)$ and $64.2( \pm 7.9)$ Gy, respectively. Patient characteristics are listed in Table 1.

\subsection{Survival and Local Control Rates}

The median follow-up duration was 10.7 months (range, 1.7-120.6 months), and 8 of the 40 patients survived during the follow-up period. Median OS and CSS times were 10.8 months (95\% CI: 2.7-18.9) and 16.3 months (95\% CI: 9.0-23.6), respectively (Figure 1). Median PFS was 6.5 months (95\% CI: 4.5-8.5), and the LC rate was 53.5\% at 1 year. Univariate and multivariate analyses revealed that there were no significant factors affecting OS. ECOG performance status and SCN involvement ( $p=0.077$ and 0.099, respectively, in multivariate analysis) appeared as marginal risk factors for CSS. Age and SCN involvement were factors influencing PFS ( $p=0.028$ and 0.039 , respectively, in multivariate analysis). For LC rates, SCN involvement and RT modality were observed as significant factors ( $p=0.034$ and 0.027 , respectively, in multivariate analysis). The results of the univariate and multivariate analyses are shown in Tables 2 and 3, respectively. Clinical characteristics between patients with and without SCN involvement were not significantly different (Supplementary Table S1). 
Table 1. Patient characteristics.

\begin{tabular}{|c|c|}
\hline Variables & $\begin{array}{l}\text { No. of Patients (\%) } \\
(\text { Total }=40)\end{array}$ \\
\hline \multicolumn{2}{|l|}{ Sex } \\
\hline Male & $32(80.0 \%)$ \\
\hline Female & $8(20.0 \%)$ \\
\hline \multicolumn{2}{|l|}{ Age (years) } \\
\hline Median (range) & $67.5(44-89)$ \\
\hline \multicolumn{2}{|l|}{ ECOG PS } \\
\hline 0 or 1 & $35(87.5 \%)$ \\
\hline 2 or higher & $5(12.5 \%)$ \\
\hline \multicolumn{2}{|l|}{ Smoking history } \\
\hline Non-smoker & $7(17.5 \%)$ \\
\hline Smoker (including ex-smoker) & $33(82.5 \%)$ \\
\hline \multicolumn{2}{|l|}{ Current smoking } \\
\hline Non-current & $28(70.0 \%)$ \\
\hline Current smoker & $12(30.0 \%)$ \\
\hline \multicolumn{2}{|l|}{ Histology } \\
\hline Squamous cell carcinoma & $26(65 \%)$ \\
\hline Adenocarcinoma & $8(20.0 \%)$ \\
\hline Not specified & $6(15 \%)$ \\
\hline \multicolumn{2}{|l|}{ T stage } \\
\hline $\mathrm{T} 1$ & $3(7.5 \%)$ \\
\hline $\mathrm{T} 2$ & $14(35.0 \%)$ \\
\hline $\mathrm{T} 3$ & $8(20.0 \%)$ \\
\hline $\mathrm{T} 4$ & $15(37.5 \%)$ \\
\hline \multicolumn{2}{|l|}{ Nodal status } \\
\hline Supraclavicular lymph node & $17(42.5 \%)$ \\
\hline Contralateral lymph node & $23(57.5 \%)$ \\
\hline \multicolumn{2}{|l|}{ RT modality } \\
\hline 3DCRT & $21(52.5 \%)$ \\
\hline IMRT & $19(47.5 \%)$ \\
\hline \multicolumn{2}{|l|}{ RT dose in EQD2 } \\
\hline 3DCRT & $60.6( \pm 6.0) \mathrm{Gy}$ \\
\hline IMRT & $64.2( \pm 7.9) \mathrm{Gy}$ \\
\hline \multicolumn{2}{|l|}{ Clinical target volume $\left(\mathrm{cm}^{3}\right)$} \\
\hline Median (range) & $292.0(77.0-1015.0)$ \\
\hline
\end{tabular}

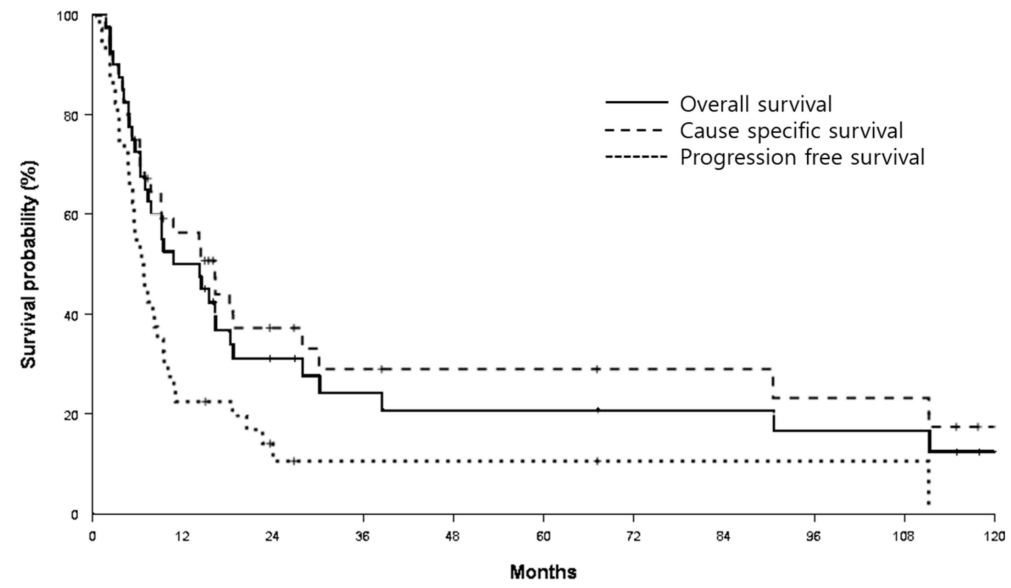

Figure 1. Overall survival (OS), cause-specific survival (CSS), and progression-free survival (PFS) outcomes. Median OS and CSS times were 10.8 months and 16.3 months. Median PFS time was 6.5 months. 
Table 2. Univariate analysis of OS, CSS, PFS, and LC rates in all patients.

\begin{tabular}{|c|c|c|c|c|c|c|c|c|c|}
\hline & $n$ & $\begin{array}{l}\text { Median } \\
\text { OS (95\% } \\
\text { CI) }\end{array}$ & $p$ Value & $\begin{array}{l}\text { Median } \\
\text { CSS (95\% } \\
\text { CI) }\end{array}$ & $p$ Value & $\begin{array}{l}\text { Median } \\
\text { PFS (95\% } \\
\text { CI) }\end{array}$ & $p$ Value & $\begin{array}{c}\text { 1-Year } \\
\text { LC\% } \\
( \pm S E)\end{array}$ & $p$ Value \\
\hline \multicolumn{10}{|c|}{ ECOG PS } \\
\hline 0 or 1 & 35 & $\begin{array}{c}14.4 \\
(6.5-22.3)\end{array}$ & & $\begin{array}{c}16.4(10.7- \\
22.1)\end{array}$ & & $\begin{array}{c}6.8 \\
(4.8-8.8)\end{array}$ & & $\begin{array}{l}56.8 \% \\
( \pm 9.7)\end{array}$ & \\
\hline 2 or higher & 5 & $\begin{array}{c}9.1 \\
(0-19.8)\end{array}$ & 0.213 & $\begin{array}{c}9.1 \\
(0-19.8)\end{array}$ & 0.117 & $\begin{array}{c}4.8 \\
(0.7-3.5)\end{array}$ & 0.274 & $0 \%$ & 0.813 \\
\hline \multicolumn{10}{|l|}{ Age, years } \\
\hline$<60$ & 9 & $\begin{array}{c}27.9(14.1- \\
41.8)\end{array}$ & & $\begin{array}{c}27.9(14.1- \\
41.8)\end{array}$ & & $\begin{array}{c}11.0 \\
(2.2-19.8)\end{array}$ & & $\begin{array}{c}55.6 \% \\
( \pm 16.6)\end{array}$ & \\
\hline$\geq 60$ & 31 & $\begin{array}{c}9.1 \\
(6.4-11.9)\end{array}$ & 0.107 & $\begin{array}{c}10.8 \\
(2.9-18.6)\end{array}$ & 0.277 & $\begin{array}{c}6.3 \\
(4.2-8.4)\end{array}$ & 0.043 & $\begin{array}{c}53.4 \% \\
( \pm 11.5)\end{array}$ & 0.635 \\
\hline \multicolumn{10}{|l|}{ Sex } \\
\hline Male & 32 & $\begin{array}{c}9.4 \\
(2.4-14.5)\end{array}$ & & $\begin{array}{c}14.4 \\
(3.2-25.6)\end{array}$ & & $\begin{array}{c}7.3 \\
(4.7-9.9)\end{array}$ & & $\begin{array}{c}55.2 \% \\
( \pm 11.1)\end{array}$ & \\
\hline Female & 8 & $\begin{array}{c}15.5 \\
(6.7-24.2)\end{array}$ & 0.776 & $\begin{array}{c}16.3 \\
(2.4-30.2)\end{array}$ & 0.801 & $\begin{array}{c}5.3 \\
(2.3-8.3)\end{array}$ & 0.151 & $\begin{array}{c}45.0 \% \\
( \pm 18.8)\end{array}$ & 0.376 \\
\hline \multicolumn{10}{|l|}{ Smoking status } \\
\hline Non-smoker & 7 & $\begin{array}{c}16.3 \\
(6.9-25.7)\end{array}$ & & $\begin{array}{c}16.3 \\
(1.7-30.9)\end{array}$ & & $\begin{array}{c}5.5 \\
(5.0-6.0)\end{array}$ & & $\begin{array}{c}51.4 \% \\
( \pm 20.4)\end{array}$ & \\
\hline Smoker & 33 & $\begin{array}{c}9.4 \\
(2.2-16.7)\end{array}$ & 0.997 & $\begin{array}{c}14.2 \\
(2.9-25.5)\end{array}$ & 0.94 & $\begin{array}{c}7.3 \\
(4.4-10.2)\end{array}$ & 0.339 & $\begin{array}{c}53.5 \% \\
( \pm 10.9)\end{array}$ & 0.809 \\
\hline \multicolumn{10}{|l|}{ Histology } \\
\hline Squamous & 26 & $\begin{array}{c}9.1 \\
(4.3-13.9)\end{array}$ & & $\begin{array}{c}10.8 \\
(0-23.8)\end{array}$ & & $\begin{array}{c}5.6 \\
(3.2-8.0)\end{array}$ & & $\begin{array}{c}63.6 \% \\
( \pm 11.7)\end{array}$ & \\
\hline Others & 14 & $\begin{array}{c}14.4(12.3- \\
16.6)\end{array}$ & 0.91 & $\begin{array}{c}18.7 \\
(9.1-28.4)\end{array}$ & 0.959 & $\begin{array}{c}6.9 \\
(5.4-8.4)\end{array}$ & 0.809 & $\begin{array}{c}38.6 \% \\
( \pm 14.8)\end{array}$ & 0.399 \\
\hline \multicolumn{10}{|l|}{ T stage } \\
\hline 1 or 2 & 17 & $\begin{array}{c}14.2 \\
(2.7-25.7)\end{array}$ & & $\begin{array}{c}16.3 \\
(12.3-2.3)\end{array}$ & & $\begin{array}{c}7.3 \\
(3.3-11.3)\end{array}$ & & $\begin{array}{c}70.7 \% \\
( \pm 12.6)\end{array}$ & \\
\hline 3 or 4 & 23 & $\begin{array}{c}9.4 \\
(1.1-17.7)\end{array}$ & 0.937 & $\begin{array}{c}14.4 \\
(2.6-26.3)\end{array}$ & 0.715 & $\begin{array}{c}6.3 \\
(4.4-8.2)\end{array}$ & 0.359 & $\begin{array}{c}39.8 \% \\
( \pm 12.8)\end{array}$ & 0.672 \\
\hline \multicolumn{10}{|c|}{ SCN involvement } \\
\hline No & 23 & $\begin{array}{c}16.4(10.0- \\
22.7)\end{array}$ & & $\begin{array}{c}18.7 \\
(3.2-34.3)\end{array}$ & & $\begin{array}{c}8.6 \\
(6.4-10.8)\end{array}$ & & $\begin{array}{c}58.2 \% \\
( \pm 12.4)\end{array}$ & \\
\hline Yes & 17 & $\begin{array}{c}7.8 \\
(4.0-11.5)\end{array}$ & 0.236 & $\begin{array}{c}7.8 \\
(4.0-11.5)\end{array}$ & 0.146 & $\begin{array}{c}4.9 \\
(2.5-7.3)\end{array}$ & 0.084 & $\begin{array}{c}47.0 \% \\
( \pm 14.4)\end{array}$ & 0.189 \\
\hline \multicolumn{10}{|l|}{ RT modality } \\
\hline 3DCRT & 21 & $\begin{array}{c}14.2 \\
(1.3-27.1)\end{array}$ & & $\begin{array}{c}18.3(10.2- \\
26.4)\end{array}$ & & $\begin{array}{c}8.0 \\
(5.9-10.1)\end{array}$ & & $\begin{array}{c}45.9 \% \\
( \pm 12.8)\end{array}$ & \\
\hline IMRT & 19 & $\begin{array}{c}10.8 \\
(3.2-18.3)\end{array}$ & 0.617 & $\begin{array}{c}14.4 \\
(6.4-22.4)\end{array}$ & 0.604 & $\begin{array}{c}5.6 \\
(4.5-6.7)\end{array}$ & 0.8 & $\begin{array}{c}62.6 \% \\
( \pm 13.6)\end{array}$ & 0.1 \\
\hline
\end{tabular}

OS, overall survival; CSS, cause-specific survival; PFS, progression-free survival; LC, local control; ECOG PS, Eastern Cooperative Oncology Group Performance Status; 3DCRT, 3-dimensional conformal radiotherapy; IMRT, intensity-modulated radiotherapy; ICI, immune checkpoint inhibitor; $\mathrm{CI}$, confidence interval; RT, radiotherapy; SE, standard error; SCN, supraclavicular node.

\subsection{Treatment-Related Toxicities}

Two patients (5\%) in the IMRT group did not complete the planned RT $(<20$ fractions) because of esophageal toxicities. Grade $\geq 3$ pneumonitis and esophagitis were found in 6 $(15.0 \%)$ and $3(7.5 \%)$ patients, respectively (Table 4$)$. No grade $\geq 3$ hemoptysis was observed. A higher RT dose (mean dose: 66.6 vs. $61.7 \mathrm{~Gy}$ ) was correlated with grade $\geq 3$ pneumonitis ( $p=0.001)$. RT modality was also a significant factor $(p=0.042)$; five of six pneumonitis cases occurred in the IMRT group (Table 5 ). In contrast, grade $\geq 3$ esophagitis was not affected by EQD2 or RT modality ( $p=0.438$ and $p=0.928$, respectively) (Supplementary Table S2). Grade 5 complications were not observed. 
Table 3. Multivariate analysis of OS, CSS, PFS, and LC rates.

\begin{tabular}{lcc}
\hline & HR (95\% CI) & $p$ Value \\
\hline OS & $2.06(0.84-5.03)$ & 0.114 \\
$\quad$ Age & $2.47(0.91-6.74)$ & \\
CSS & $1.97(0.88-4.40)$ & 0.077 \\
$\quad$ ECOG PS & & 0.099 \\
$\quad$ SCN involvement & $2.79(1.12-6.96)$ & 0.028 \\
PFS & $2.08(1.04-4.17)$ & 0.039 \\
$\quad$ Age & $3.05(1.09-8.50)$ & 0.034 \\
$\quad$ SCN involvement & $0.28(0.09-0.86)$ & 0.027 \\
Local control rates & SCN involvement & \\
$\quad$ IMRT use & OS, overall survival; CSS, cause-specific survival; PFS, progression-free survival; LC, local control; ECOG PS, \\
Eastern Cooperative Oncology Group Performance Status; SCN, supraclavicular node; IMRT, intensity-modulated \\
radiotherapy; HR, hazard ratio; CI, confidence interval.
\end{tabular}

Table 4. Toxicities experienced by all patients receiving radiochemotherapy.

\begin{tabular}{cccc}
\hline & Grade 2 & Grade 3 & Grade 4 \\
\hline Pneumonitis & $15.0 \%$ & $7.5 \%$ & $7.5 \%$ \\
Esophagitis & $50.0 \%$ & $7.5 \%$ & $0.0 \%$ \\
Hemoptysis & $7.5 \%$ & $0.0 \%$ & $0.0 \%$ \\
\hline
\end{tabular}

Table 5. Factors related to Grade $\geq 3$ pneumonitis.

\begin{tabular}{|c|c|c|c|}
\hline & $\begin{array}{c}\text { No Complication } \\
(n=34)\end{array}$ & $\begin{array}{c}\text { Grade } \geq 3 \\
\text { Pneumonitis }(n=6)\end{array}$ & $p$ Value * \\
\hline EQD2 (continuous) & $61.7 \pm 7.4$ & $66.6 \pm 0.9$ & 0.001 \\
\hline EQD2 & & & 0.056 \\
\hline$<63 \mathrm{~Gy}$ & $19(55.9 \%)$ & $1(16.6 \%)$ & \\
\hline$\geq 63 \mathrm{~Gy}$ & $15(44.1 \%)$ & $5(83.3 \%)$ & \\
\hline $\begin{array}{l}\text { Radiation therapy } \\
\text { modality }\end{array}$ & & & 0.042 \\
\hline 3DCRT & $20(58.8 \%)$ & $1(16.7 \%)$ & \\
\hline IMRT & $14(41.2 \%)$ & $5(83.3 \%)$ & \\
\hline Volume of CTV & $349.2 \pm 226.1$ & $531.6 \pm 337.0$ & 0.2 \\
\hline Mean lung dose & $1436.7 \pm 527.7$ & $1439.1 \pm 618.6$ & 0.994 \\
\hline V20 & $28.4 \pm 15.0$ & $17.2 \pm 2.9$ & 0.208 \\
\hline
\end{tabular}

\subsection{Patterns of Failure}

During follow-up, 23 patients (57.5\%) had treatment failure. Local failure (in-field failure) occurred in $18(45.0 \%)$ of the 40 patients. Distant out-of-field failure was observed in $12(30.0 \%)$ patients, and both local and distant metastases occurred in seven (17.5\%) patients.

\section{Discussion}

Regarding OS, median survival time was 10.8 months in our cohort, which is comparable to the results of N3 patients mentioned in the IASLC database (10 months), wherein patients were diagnosed during 1999-2010 [6]. Although our cohort was recruited from 2010 to 2019, a similar oncologic outcome could be expected because the dose or modality of RT and concomitant chemotherapy have not changed significantly. Local failure occurred in $45 \%$ of patients, which is comparable to the result reported in other clinical series investigating patients with stage IIIB or higher $[12,16]$, necessitating further optimization of locoregional treatment. Grade $\geq 3$ complication rates of pneumonitis and esophagitis 
accounted for $15 \%$ and $7.5 \%$ of all cases, respectively, although not negligible, suggesting the feasibility of radiochemotherapy for N3-IIIC patients.

Auperin et al. [7] conducted a meta-analysis regarding concomitant radiochemotherapy for locally advanced NSCLC and reported that survival gain (hazard ratio (HR) 0.84 , $p=0.004$ ) was attributed to decreased locoregional recurrence (HR $0.77, p=0.01$ ) rather than distant recurrence (HR 1.04, $p=0.69$ ). Therefore, dose escalation to achieve local control has been investigated in various studies, although the benefit of escalation for more than 60 Gy has yet to be clarified [17]. In our study, the use of IMRT was a significant factor that increased the local control rate $(p=0.027)$. In a descriptive analysis, $61.9 \%$ of patients who underwent 3DCRT experienced locoregional recurrence during follow-up, whereas the corresponding rate was $26.3 \%$ in those who underwent IMRT. Although dose difference was not significant between modalities $(p=0.105)$, excluding two patients who underwent incomplete RT in IMRT arms ( $<20$ fractions), the IMRT arm received a higher dose than the 3DCRT arm (mean 66.4 vs. $60.6 \mathrm{~Gy}, p=0.002$ ). Therefore, we assumed that dose escalation achieved with the help of more conformal modality, which is IMRT herein, might help in achieving higher local control. Notably, the IMRT arm showed higher local control, despite having a larger clinical target volume (i.e., the target volume of which is planned to receive the prescribed dose with borderline significance, mean $439 \mathrm{vs.} 294 \mathrm{cc}$, $p=0.06$ ) (Supplementary Table S2). However, the higher rate of local control leads to respiratory complication; the patients who experienced grade $\geq 3$ pneumonitis were prescribed significantly higher dose of radiation (mean 66.6 vs. $61.7 \mathrm{~Gy}, p=0.001$ ).

The prognostic impact of SCN involvement, compared to other mediastinal N3 diseases, is not yet well investigated. Many studies have investigated the clinical impact of nodal metastases according to location, involving a heterogeneous group of patients [12]. Furthermore, in studies according to the AJCC 7th edition or earlier staging system, stage IIIB covered not only N3 cases but also T4N2 cases [11]. Oh et al. [12]. recently reported that SCN involvement did not have a negative effect on oncologic outcomes, as compared to contralateral mediastinal involvement. In their study, OS and PFS were not significantly different according to SCN involvement $(p=0.679$ and $p=0.223$ for OS and PFS, respectively). However, in our study, SCN involvement was a factor negatively affecting CSS with borderline significance (HR: 1.97, $p=0.099$ ), and a significant factor regarding local control (HR: 3.05, $p=0.034$ ). Regarding biological structure, although lymphatic drainage from the lungs is generally ipsilateral, contralateral drainage through the subcarinal lymphatic channel is not uncommon, especially for those with disease in the lower lobes. In comparison, involvement of the SCN is regarded as a terminal lymphatic station before entering the venous system, and is therefore known to be related to tumor recurrence or metastases [18-20]. The current paucity of clinical literature regarding the prognostic impact of SCN involvement in stage IIIC patients necessitates further clinical research.

The small number of patients and the retrospective design are limitations of the current study. Some non-significant covariates in univariate analysis became significant in multivariate analysis, probably because of the suppression effect, which can be observed in a small case series [15]. However, the present study has the merit of providing clinical data solely for N3-IIIC patients, which has been scarce in previous literature. Further large-sized or multicenter trials can help understand the clinical course of N3-IIIC patients, including the prognostic impact of SCN involvement.

To summarize, our study showed that definitive radiochemotherapy was feasible for patients with stage IIIC. The application of IMRT with a higher dose could help enhance local control, and it possibly affected the occurrence of grade $\geq 3$ pneumonitis. Therefore, planning optimization to reduce bystander irradiation on normal organs while maintaining a sufficient dose to tumors, or the application of particle therapy for further optimization, should be further investigated. The application of immunotherapy, which includes the use of drugs such as durvalumab [21], is expected to further increase the outcome, although none of the patients in the present study received it. The clinical impact of SCN involve- 
ment in stage IIIC patients should also be investigated to provide further optimized and personalized treatments.

\section{Conclusions}

Our study showed definitive radiochemotherapy for N3-positive NSCLC patients was feasible and yielded comparable oncologic outcomes. High dose irradiation with IMRT can increase local control, but might cause grade $\geq 3$ pneumonitis.

Supplementary Materials: The following are available online at https:/ /www.mdpi.com/1648-914 4/57/3/301/s1, Table S1: Clinical characteristics between patients with and without supraclavicular lymph node (SCN) involvement, Table S2: Toxicity parameters and radiation profile according to the radiation therapy modality.

Author Contributions: Conceptualization, C.H.R. and S.P.; methodology, S.P.; software, S.P. and C.H.R.; validation, W.S.Y., C.H.R., and S.P.; formal analysis, S.P.; investigation, M.H.J.; resources, W.S.Y.; data curation, M.H.J.; writing—original draft preparation, S.P.; writing—review and editing, C.H.R.; visualization, S.P.; supervision, W.S.Y.; project administration, W.S.Y.; funding acquisition, C.H.R. All authors have read and agreed to the published version of the manuscript.

Funding: This study was supported by the National Research Fund of Korea (NRF-2019M2D2A1A01046998). The funders had no role in the study design, main results, and decision to publish.

Institutional Review Board Statement: The authors are accountable for all aspects of the work in ensuring that questions related to the accuracy or integrity of any part of the work are appropriately investigated and resolved. This study was approved by the Institutional Review Board of Korea University Medical Center (IRB number: 2020AS0244).

Informed Consent Statement: Patient consent was waived because our study did not use any personally identifiable information and did not pose any harm to the patients.

Data Availability Statement: The data that support the findings of this study are available from the corresponding author, C.H.R., upon reasonable request.

Conflicts of Interest: The authors declare no conflict of interest. The funders had no role in the design of the study; in the collection, analyses, or interpretation of data; in the writing of the manuscript; or in the decision to publish the results.

\section{References}

1. NCCN. NCCN Guidelines Version 2.2021. Non-Small Cell Lung Cancer. Available online: https://www.nccn.org/professionals/ physician_gls/pdf/nscl.pdf (accessed on 6 January 2021).

2. $\quad$ Ramnath, N.; Dilling, T.J; Harris, L.J; Kim, A.W.; Michaud, G.C.; Balekian, A.A.; Diekemper, R.; Detterbeck, F.C.; Arenberg, D.A. Treatment of stage III non-small cell lung cancer: Diagnosis and management of lung cancer, 3rd ed: American College of Chest Physicians evidence-based clinical practice guidelines. Chest 2013, 143 (Suppl. 5), e314S-e340S. [CrossRef] [PubMed]

3. Shepherd, F.A.; Crowley, J.; Van Houtte, P.; Postmus, P.E.; Carney, D.; Chansky, K.; Shaikh, Z.; Goldstraw, P. The International Association for the Study of Lung Cancer lung cancer staging project: Proposals regarding the clinical staging of small cell lung cancer in the forthcoming (seventh) edition of the tumor, node, metastasis classification for lung cancer. J. Thorac. Oncol. 2007, 2, 1067-1077. [CrossRef] [PubMed]

4. Noh, J.M.; Kim, J.M.; Ahn, Y.C.; Pyo, H.; Kim, B.; Oh, D.; Ju, S.G.; Shin, J.S.; Hong, C.-S.; Park, H.; et al. Effect of Radiation Therapy Techniques on Outcome in N3-positive IIIB Non-small Cell Lung Cancer Treated with Concurrent Chemoradiotherapy. Cancer Res. Treat. 2016, 48, 106-114. [CrossRef] [PubMed]

5. Russell, K.; Healy, B.; Pantarotto, J.; Laurie, S.A.; Macrae, R.; Sabri, E.; Wheatley-Price, P. Prognostic factors in the radical nonsurgical treatment of stage IIIB non-small-cell lung cancer. Clin. Lung Cancer 2014, 15, 237-243. [CrossRef] [PubMed]

6. Asamura, H.; Chansky, K.; Crowley, J.; Goldstraw, P.; Rusch, V.W.; Vansteenkiste, J.F.; Watanabe, H.; Wu, Y.L.; Zielinski, M.; Ball, D.; et al. The International Association for the Study of Lung Cancer Lung Cancer Staging Project: Proposals for the Revision of the N Descriptors in the Forthcoming 8th Edition of the TNM Classification for Lung Cancer. J. Thorac. Oncol. 2015, 10, 1675-1684. [CrossRef] [PubMed]

7. Aupérin, A.; Le Péchoux, C.; Rolland, E.; Curran, W.J.; Furuse, K.; Fournel, P.; Belderbos, J.; Clamon, G.; Ulutin, H.C.; Paulus, R.; et al. Meta-analysis of concomitant versus sequential radiochemotherapy in locally advanced non-small-cell lung cancer. J. Clin. Oncol. 2010, 28, 2181-2190. [CrossRef] [PubMed] 
8. $\quad$ Rodrigues, G.; Choy, H.; Bradley, J.; Rosenzweig, K.E.; Bogart, J.; Curran, W.J., Jr.; Gore, E.; Langer, C.; Louie, A.V.; Lutz, S.; et al. Definitive radiation therapy in locally advanced non-small cell lung cancer: Executive summary of an American Society for Radiation Oncology (ASTRO) evidence-based clinical practice guideline. Pract. Radiat. Oncol. 2015, 5, 141-148. [CrossRef] [PubMed]

9. Bradley, J.D.; Ieumwananonthachai, N.; Purdy, J.A.; Wasserman, T.H.; Lockett, M.A.; Graham, M.V.; Perez, C.A. Gross tumor volume, critical prognostic factor in patients treated with three-dimensional conformal radiation therapy for non-small-cell lung carcinoma. Int. J. Radiat. Oncol. 2002, 52, 49-57. [CrossRef]

10. Wiersma, T.G.; Dahele, M.; Verbakel, W.F.; Van De Ven, P.M.; De Haan, P.F.; Smit, E.F.; Van Reij, E.J.; Slotman, B.J.; Senan, S. Concurrent chemoradiotherapy for large-volume locally-advanced non-small cell lung cancer. Lung Cancer 2013, 80, 62-67. [CrossRef] [PubMed]

11. Machtay, M.; Seiferheld, W.; Komaki, R.; Cox, J.D.; Sause, W.T.; Byhardt, R.W. Is prolonged survival possible for patients with supraclavicular node metastases in non-small cell lung cancer treated with chemoradiotherapy?: Analysis of the Radiation Therapy Oncology Group experience. Int. J. Radiat. Oncol. 1999, 44, 847-853. [CrossRef]

12. Oh, D.; Ahn, Y.C.; Park, H.C.; Lim, D.H.; Noh, J.M.; Cho, W.K.; Pyo, H. The prognostic impact of supraclavicular lymph node in N3-IIIB stage non-small cell lung cancer patients treated with definitive concurrent chemo-radiotherapy. Oncotarget 2017, 8, 35700-35706. [CrossRef] [PubMed]

13. Kaplan, E.L.; Meier, P. Nonparametric Estimation from Incomplete Observations. J. Am. Stat. Assoc. 1958, 53, 457-481. [CrossRef]

14. Lin, D.Y. Cox regression analysis of multivariate failure time data: The marginal approach. Stat. Med. 1994, 13, 2233-2247. [CrossRef] [PubMed]

15. Thompson, F.T.; Levine, D.U. Examples of easily explainable suppressor variables in multiple regression research. Mult. Linear Regres. Viewp. 1997, 24, 11-13.

16. Topkan, E.; Ozdemir, Y.; Guler, O.C.; Kucuk, A.; Besen, A.A.; Mertsoylu, H.; Sezen, D.; Akdemir, E.Y.; Sezer, A.; Bolukbasi, Y.; et al. Comparison of Involved Field Radiotherapy versus Elective Nodal Irradiation in Stage IIIB/C Non-Small-Cell Lung Carcinoma Patients Treated with Concurrent Chemoradiotherapy: A Propensity Score Matching Study. J. Oncol. 2020, 2020, 7083149. [CrossRef] [PubMed]

17. Ma, L.; Men, Y.; Feng, L.; Kang, J.; Sun, X.; Yuan, M.; Jiang, W.; Hui, Z. A current review of dose-escalated radiotherapy in locally advanced non-small cell lung cancer. Radiol. Oncol. 2019, 53, 6-14. [CrossRef]

18. Brotons, M.L.; Bolca, C.; Fréchette, É.; Deslauriers, J. Anatomy and physiology of the thoracic lymphatic system. Thorac. Surg. Clin. 2012, 22, 139-153. [CrossRef] [PubMed]

19. Jackson, M.A.; Chesney, P.J. Lymphatic system and generalized lymphadenopathy. In Principles and Practice of Pediatric Infectious Diseases; Elsevier: Amsterdam, The Netherlands, 2012; pp. 127-135.e1.

20. Mizutani, M.; Nawata, S.; Hirai, I.; Murakami, G.; Kimura, W. Anatomy and histology of Virchow's node. Anat. Sci. Int. 2005, 80, 193-198. [CrossRef] [PubMed]

21. Faivre-Finn, C.; Vicente, D.; Kurata, T.; Planchard, D.; Paz-Ares, L.; Vansteenkiste, J.; Spigel, D.; Garassino, M.; Reck, M.; Senan, S.; et al. LBA49 Durvalumab after chemoradiotherapy in stage III NSCLC: 4-year survival update from the phase III PACIFIC trial. Ann. Oncol. 2020, 31, S1178-S1179. [CrossRef] 